\title{
A panoramic view on metadata application profiles of the last decade
}

\section{Mariana Curado Malta*}

\author{
Algoritmi Center, \\ University of Minho, \\ Guimarães, Portugal \\ and \\ Polytechnic of Oporto, \\ Porto, Portugal \\ Email: mariana.malta@algoritmi.uminho.pt \\ *Corresponding author
}

\section{Ana Alice Baptista}

\author{
Algoritmi Center, \\ University of Minho, \\ Guimarães, Portugal \\ Email: analice@dsi.uminho.pt
}

\begin{abstract}
This paper describes a study developed with the goal to understand the panorama of the metadata Application Profiles (AP): (i) what AP have been developed so far; (ii) what type of institutions have developed these AP; (iii) what are the application domains of these AP; (iv) what are the Metadata Schemes (MS) used by these AP; (v) what application domains have been producing MS; (vi) what are the Syntax Encoding Schemes (SES) and the Vocabulary Encoding Schemes (VES) used by these AP; and finally (vii) if these AP have followed the Singapore Framework (SF). We found (i) 74 AP; (ii) the AP are mostly developed by the scientific community, (iii) the 'Learning Objects' domain is the most intensive producer; (iv) Dublin Core metadata vocabularies are the most used and are being used in all domains of application and IEEE LOM is the second most used but only inside the 'Learning Objects' application domain; (v) the most intensive producer of MS is the domain of 'Libraries and Repositories'; (vi) 13 distinct SES and 90 distinct VES were used; (vi) five of the 74 AP found follow the SF.
\end{abstract}

Keywords: metadata; application profile; Dublin Core; Dublin Core Application Profile; Singapore Framework recommendation; Semantic Web; interoperability; interoperability levels.

Reference to this paper should be made as follows: Curado Malta, M. and Baptista, A.A. (2014) 'A panoramic view on metadata application profiles of the last decade', Int. J. Metadata, Semantics and Ontologies, Vol. 9, No. 1, pp.58-73.

Biographical notes: Mariana Curado Malta graduated in Electrical Engineering and Computers and she is presently finishing her $\mathrm{PhD}$ in Information Systems and Technologies in the University of Minho, Guimarães, Portugal. She is also a Lecturer at the Polytechnic of Oporto, Porto, Portugal, in the School of Accounting and Administration. Her PhD thesis work aims to contribute to the definition of a method for the development of Dublin Core Application Profiles, a construct of the Semantic Web. Her research interest is the Semantic Web. She is also very interested in working in projects that build bridges between the social and technological aspects of the organisations.

Ana Alice Baptista is a Professor at the Information Systems Department, University of Minho, Portugal. She graduated in Computer Engineering and has a PhD in Information Systems and Technologies. She is a member of the DCMI Advisory Board and of the Elpub conference series Executive Committee. She participated in several R\&D projects and she was an evaluator of project's proposals under FP7. She has authored or co-authored more than 40 articles. Her main areas of interest include Semantic Web, digital libraries and scholarly communication on both their technological and social perspectives. Additional information can be found at http://www. dsi.uminho.pt/-analice. 


\section{Introduction}

The Semantic Web is about common formats for integration and combination of data from different sources (W3C, 2012). This data is mostly what is being called metadata, in the way that it is 'data about data' (DCMI, 2011) and follows well-defined rules of metadata schemes (also called vocabularies). A metadata scheme is a set of "metadata elements designed for a specific purpose, such as describing a particular type of information resource" (Press, 2004, p.4).

The Dublin Core Metadata Initiative (DCMI; see http:// dublincore.org/) created new instruments so that those involved in the definition of metadata descriptions could speak a common language. These new instruments appeared with the aim of adapting the metadata community to the transformations the Semantic Web has brought about. The Dublin Core Abstract Model (DCAM) appears with this purpose: it is a model developed by DCMI, for DCMI syntax specifications, that presents the components and constructs used in DCMI metadata. One of these constructs used in DCMI is the Dublin Core Application Profile (DCAP), "a generic construct for designing metadata records" Baker and Coyle (2009). The "Singapore Framework for Dublin Core Application Profiles" recommendation (see Baker et al., 2008) defines the rules to build a DCAP.

This DCMI work has been developed under the hat of international standards. Actually, the use of these international standards is critical when it comes to semantic interoperability, but it is not sufficient, since to achieve high levels of interoperability a community needs to follow some rules. These rules are defined in the interoperability layers model (cf. Nilsson et al., 2009), which allows a community to assess the 'interoperability reach' of a particular implementation. This model defines four levels of interoperability. When we talk about resources description using metadata schemes, these four levels have to do with the use of (i) metadata schemes and DCMI vocabularies (Dublin Core Metadata Element Set and DCTERMS), in levels 1 and 2, and (ii) DCMI standards, DCAM and DCAP, in levels 3 and 4.

Level 4 is the highest level of interoperability defined by DCMI, and it is achieved when a community uses the DCAP construct as a reference and binding to describe its resources. A DCAP became a very important instrument to implement interoperability; that is the reason why it is so important to understand where the metadata community is concerning the development of DCAP.

This paper reports on a study about metadata application profiles that have been developed the last decade in the metadata community. The goal of the study was to understand the panorama of the metadata application profiles in what concerns (i) what metadata application profiles have been developed so far; (ii) what type of institutions have developed these application profiles (iii) what are the application domains of these metadata application profiles; (iv) what are the metadata schemes used by these metadata application profiles; (v) what application domains have been producing metadata schemes; (vi) what are the syntax encoding schemes and the vocabulary encoding schemes used by these metadata application profiles; and finally (vii) the Singapore Framework assessment for these metadata application profiles.

This article is organised in six sections. In Section 2, we explore the concept of an application profile. Section 3 lists some limitations of the study and its scope. Section 4 presents the methodology. Section 5 presents the results and, finally, closing conclusions and future work are drawn in Section 6.

\section{Application profiles}

Any standard was always a basis for the implementation of profiles (even before the existence of the internet). A good example was the community Z39.50 (see http://www. loc.gov/z3950/agency/) which created profiles to refine the standard options (Baker et al., 2001). An AP was based on a standard, and it was a technique that helped a certain community to refine the standard to their needs (Lynch, 1997).

Later, with the Semantic Web, and with the advent of the RDF syntax, a standard model for web data interchange (W3C, 2010), programmers had the technology for the combination of individual elements of a variety of different metadata schemes. It was an open gate to the possibility of choosing the most appropriate elements to describe resources (Heery and Patel, 2000). Heery and Patel (2000) define an AP as consisting of "Data elements drawn from one or more namespaces schemas combined together by implementors and optimised for a particular local application".

The DCMI (cf. http://www.dublincore.org), probably the most well-known and influential worldwide initiative in what concerns metadata, in order to provide "a foundation for the development of application-independent syntax specifications and constraint languages", developed the DCAM (Powell et al., 2007) that presents the components and constructs used in DCMI metadata. One of these constructs is the DCAP, "a generic construct for designing metadata records" (Baker and Coyle, 2009). The definition of rules to build a DCAP is set in the "Singapore Framework for Dublin Core Application Profiles", a DCMI recommendation (cf. Nilsson, 2008). According to the Singapore Framework, a DCAP is composed of

- functional requirements,

- domain model,

- description set profile,

- $\quad$ usage guidelines (optional),

- $\quad$ syntax guidelines (optional).

The Singapore Framework is a synopsis of all the research done among the metadata community until that date. It is a very important document since it defines a framework to implement semantic interoperability among different communities of practice. Semantic interoperability focuses on meaningful exchanges of information, i.e. the information has the same interpretation - or very closely - by both the sender and the receiving systems. 
Table 1 The evolution of the application profile definition

\begin{tabular}{lll}
\hline \multicolumn{1}{c}{ Source } & \multicolumn{1}{c}{ Brief definition } & \multicolumn{1}{c}{ Comments } \\
\hline Lynch (1997) & $\begin{array}{l}\text { An AP is based on a standard, and it is a technique that } \\
\text { helps a certain community to refine the standard to their To refine a standard. } \\
\text { needs. }\end{array}$ \\
\hline Heery and Patel (2000) & $\begin{array}{l}\text { Data elements drawn from one or more namespaces } \\
\text { schemas combined together by implementors and } \\
\text { optimised for a particular local application. }\end{array}$ & $\begin{array}{l}\text { The possibility of 'mixing and matching' different } \\
\text { metadata schemes. }\end{array}$ \\
\hline Baker et al. (2008) & $\begin{array}{l}\text { An AP as a process adds to the previous definition the A more complete, comprehensive definition: (i) } \\
\text { need to build: functional requirements, domain model, forcing developers to do better AP development } \\
\text { description set profile, usage guidelines and syntax processes and (ii) suggesting them to provide AP } \\
\text { guidelines. }\end{array}$ & \begin{tabular}{l} 
documentation to help AP implementors. \\
\hline
\end{tabular}
\end{tabular}

For the sake of our work, when we refer to an AP, we refer to metadata profile implementations that meet the definitions of either Lynch (1997) or Heery and Patel (2000) or Baker et al. (2008).

From the 1997 definition by Lynch (1997) to the 2008 definition by Baker et al. (2008), we can see a clear evolution (cf. Table 1). Lynch (1997) defines an AP as a refinement of a standard; Heery and Patel (2000) go beyond defining an AP as 'mixing and matching' of different metadata schemes; finally, Baker et al. (2008) see an AP development as a process. And, in order to build more meaningful, comprehensive AP, they add to the previous approach the need to describe the different metadata schemes' properties and constraints through the use of the description set profile constraint language (cf. Nilsson, 2008); the need to define functional requirements and a data model in order to force AP developers to have better development processes; and the need to develop guidelines (even if not mandatory) in order to provide AP implementors with better documentation.

\section{Scope and limitations of the study}

Our study was developed between March 2012 and January 2013; its purpose was to study all the AP of the metadata community. We are aware that this task is complex and perhaps impossible to perform in its entirety.

We only speak a few languages. Articles written in languages other than Portuguese, Spanish, English and French were out of reach. Although we could find an AP in Norwegian and another in Dutch, it was difficult to understand the documentation, despite the help of Google Translate (http://translate.google.com).

Some AP are not being used, their website no longer exists or has no available information or contact person. They are referred in several scientific articles (cf. Godby, 2004; de La Passadière and Jarraud, 2004; Manouselis et al., 2009). It is not possible to study the AP that have not published any scientific article and do not have a website. Examples include The curriculum on-line; Learning and Teaching Scotland application Profile; SingCORE and UFI.

We have found some dispersion of nomenclature: developers assign different names to an AP. Searches become more complex when we have so many names for what we call AP.

\section{Methodology}

\subsection{Literature review and other work efforts}

In order to find AP of the metadata community, we started with a literature review. We carried out general searches and then more refined searches in the following online databases: Google Scholar (http://scholar.google.com), ISI Web of Knowledge (http://www.isiWebofknowledge.com), Networked Digital Library of Thesis and Dissertations (http:// www. ndltd. org/serviceproviders/scirus-etd-search), Scopus (http:// www. scopus.com) and Oaister (http://oaister. worldcat.org). The searches were made in English, French, Spanish and Portuguese in the fields 'title of the article', 'subject of the article' and 'body of the article'.

In the first phase of the searches, we chose a set of articles.

In the second phase, we analysed the references of the articles chosen in the first phase; new articles were chosen due to the relevance of their titles and later the relevance of their abstracts. This process was iterative in what new articles were concerned, ending when no new articles could be found.

In the third phase, we looked for articles citing the articles of the first phase. New articles were selected according to the same rules of the second phase.

The keywords used for the searches were Metadata Application Profile, Dublin Core Application Profile, Metadata Element Set, Metadata Scheme and Metadata vocabulary.

After the literature review, we have made efforts to find more metadata application profiles through the following:

- Google (http://www.google.com) searches with the same keywords defined in the literature review;

- Posts on the 'General' DCMI mailing list (dc-general @jiscmail.ac.uk) calling for information on AP development;

- Existing information in the 'Architecture' DCMI mailinglist (dc-architecture@jiscmail.ac.uk).

\subsection{Application profile analysis}

To analyse the AP, we have followed the method used by Manouselis et al. (2010): a number of analysis dimensions have been incorporated into an Openoffice-Calc file. The analysis of the AP was divided into three sets of dimensions described in Subsections 4.2.1, 4.2.2 and 4.2.3. 


\subsubsection{Description of the first set of dimensions}

The first set of dimensions chosen for the analysis has to do with information about the name of the AP and the year of development of the AP, type of institution that developed the AP, domain and sub-domain of the AP, and the Singapore Framework assessment of the AP:

Acronym

AP given acronym.

Year

AP publication year. This information was taken either from the technical documentation or from the scientific article.

Name

Name given to the AP.

Type

The type of institution or community that developed the AP. We created a categorisation for this field as listed in Table B1, e.g. Scientific community, Regional Group of People, International Government.

\section{Domain}

Context, community, area of application for which the AP was developed. We created a categorisation for this field. A new category would be created every time we would have found more than one AP with the same application domain. At the end of the analyses, all the AP without a category were gathered in the category 'Other'. Table B2 and Appendix A show the list of categories for the domain field, e.g. Agriculture, Learning Objects.

\section{Sub-domain}

A sub-domain within the domain (previous field) for which the AP was developed, when it is defined, e.g. domain 'Learning Objects', sub-domain 'Agriculture'; a Learning Object AP that was developed specifically for the agriculture domain.

\section{Version}

AP version. We have used ' $\mathrm{n} / \mathrm{a}$ ' when there was no information about the version.

\section{Singapore}

Assessment of the Singapore Framework. An application profile has followed the Singapore Framework if it has defined its functional requirements, its domain model and its description set profile (for more information on the Singapore Framework, see http://dublincore.org/ documents/ singapore-framework/). If the AP follows the Singapore Framework, the value is ' 1 ', otherwise it is ' 0 '.

Based

Metadata schemes used in the AP.

New terms

AP use of new terms (added to the selected metadata schemes - previous point). If used, the value is ' 1 ', otherwise it is ' 0 '.

\section{Binding}

Technological link available. We used 'XML' or 'RDF'; in case none of the previous is present, we used ' 0 '.

FR

Functional requirements as defined by the Singapore Framework. We used ' 1 ' if the AP has defined the functional requirements, otherwise ' 0 '.

$D M$

Domain model as defined by the Singapore Framework. We used ' 1 ' if the AP has defined a domain model, otherwise ' 0 '.

\section{$D S P$}

Description set profile as defined in the Singapore Framework. We used ' 1 ' if there is DSP description of the AP, otherwise ' 0 '.

Use

Usage guidelines as defined in the Singapore Framework. We use ' 1 ' if the AP has usage guidelines, otherwise ' 0 '.

$U R L$

Website with information about the AP. We used ' $\mathrm{n} / \mathrm{a}$ ' when there is no information regarding the website.

$U R I$

URI of the RDF document describing the AP. We used ' $n / a$ ' when there was no evidence that the AP had an RDF representation.

\subsubsection{Description of the second set of dimensions}

The second set of dimensions chosen for the analysis has to do with the metadata schemes used by the AP. These metadata schemes were classified as shown in Table B3. Our second set of dimensions includes the following:

Acronym

Acronym of the metadata scheme.

Name

Name of the metadata scheme.

$U R L$

URL with information about the metadata scheme. We used ' $\mathrm{n} / \mathrm{a}$ ' when there is no information regarding the website.

\section{$U R I$}

URI of the RDF document describing the metadata scheme. We used ' $n / a$ ' when there was no evidence that the metadata scheme had an RDF representation.

\subsubsection{Description of the third set of dimensions}

The third set of dimensions chosen for the analysis has to do with the syntax encoding schemes and the vocabulary 
encoding schemes used by the AP. Since we are working in the Semantic Web context, we kept only the encoding schemes that have a URI of the RDF documents describing the encoding schemes. Our third set of dimensions includes the following:

\section{Label}

The name of the encoding scheme.

\section{Definition}

A definition of the encoding scheme.

\section{$U R I$}

The URI of the RDF document describing the encoding scheme. We used ' $\mathrm{n} / \mathrm{a}$ ' when there was no evidence that the encoding scheme had an RDF representation.

\section{See}

A URL with information about the encoding scheme. We used ' $\mathrm{n} / \mathrm{a}$ ' when there is no information regarding the website.

\subsubsection{Document analysis}

The searches and other work described in Section 4.1 include a set of documents and websites with information about AP. These documents are scientific articles, technical documents and websites. Some of the AP had these three types of items, others only one or two. We then analysed these documents to obtain information for every dimension described in Sections 4.2.1, 4.2.2 and 4.2.3. The steps followed for document analyses were as follows:

- The scientific articles published by the AP developers were always the starting point for the analysis. When necessary, we used the references in the articles to consult technical documentation, or the website of the AP, looking for more information. When none of these references was enough to perform our analysis, the authors of the article were contacted by email.

- If there was no scientific article of a certain AP, we analysed its technical documents if available or as last resource, the websites of the AP. When necessary, we sent an email to the available contacts on the website.

In the cases that we did not find information for a certain dimension in none of the previous sources described, the value used in the fields with no information was set to ' $\mathrm{n} / \mathrm{a}$ '. The distinction between ' $\mathrm{n} / \mathrm{a}$ ' and ' 0 ' is that the first means that no information could be found despite all document analyses, while the latter means that it does not exist, that it was not defined, e.g. if the DSP was not found in the technical documents of the AP, the field 'DSP' was set to ' 0 '. It is indeed not available, but the technical documents were analysed and did not have the DSP description. On the contrary, if there were no technical documents available, the DSP value field would be set to ' $\mathrm{n} / \mathrm{a}$ '.

\section{Results}

We selected a total of 83 AP, the oldest from 2001 and the most recent from 2012. However, nine of them were excluded for one or more of the following reasons:

- There was no information concerning the metadata schemes used to describe the metadata records of the AP.

- Despite all efforts referred to in Section 4.2.4, it was not possible to find consistent information about the AP.

- The definitions of the AP are not public or the called AP was not in fact an AP since it only presented a conceptual scheme.

Detailed results are available in Matrix-I (first set of dimensions), Matrix-II (second set of dimensions) and Matrix-III (third set of dimensions) datasets stored in the institutional repository of the University of Minho, accessible through the handle http://hdl.handle.net/1822/ 23412. This handle also provides a file containing the raw data.

\subsection{What AP have been developed so far}

The analysed AP were (listed by domain of application and in alphabetical order):

\section{Agriculture}

Ag-Event AP, Ag-Job AP, AGRIS, FiMES, Organisation AP.

Cross-Domain

Audiovisual AP, AGLS, DC-EM AP, NZGLS, TBM-AP, VMAP.

Cultural Heritage

EDMMAG, EMAP, ESE, Folklore Description AP, PICO, QuinkMAp

\section{E-Government}

ADMS, DC-Gov, e-GMS, GO-WMES, OWMS, PSI AP

\section{Learning Objects}

Ag-LR, ANZ LOM, AraCore, BEN, CanCore AP, Celebrate AP, CerOrganic AP, CG LOM, DC-Edu, Edna, FAILTE, FERL, HLSI, LOMAP, LORELOM, LRE AP, ManUel, MELT, MIMETA, Normetic, NORMLOM, OpenCartable, Organic Edu.net, ReGov, RLLOMAP, scoLOMFR, SCORM, TLF AP, UK LOM Core, Vedata.

\section{Libraries/Repositories}

DC-CDAP, DC-LIB, DRC AP, MAP, Michael-eu DCAP, MPEG21 DIDL, NLM MS, OAI-DC, RENAP, TDL ETD MOS.

Science

APIARY AP, DRYAD, MLAP, SWAP. 
Other

\section{CRAP, DC2AP, IAP, IOAP, OAI-ORE.}

A detailed list of the analysed AP with a reference to the main source of information can be found in Table 5 and Appendix A. These AP are organised by domain of application and ordered per year, and in every year, in alphabetical order.

\subsection{What type of institutions have developed the AP}

The calculation of the frequency of AP per type of institution (see Table 2) demonstrated that AP are mostly developed by the 'Scientific Community' group with 23 AP developed (31.1\%), by the 'International Organisation/ Company' group with 13 AP (17.6\%) developed and by the 'National Government' group with 11 AP (14.9\%) developed. These three groups are $63.5 \%$ of the whole AP developers. Then follows the 'International Group of People', the 'National Group of People', the 'National Organisation/Community', the 'Regional Group of People' that developed five AP each (6.8\%); then follows the 'International Government' developed two AP (2.7\%) and finally the 'Regional Organisation/Company' group that developed one AP (1.50\%). Four AP (5.4\%) did not have any information about the characteristics of the organisation or group of individuals behind the AP development.

Table 2 Frequency of AP per type of institution

\begin{tabular}{ccl}
\hline$\%$ & $\#$ & \multicolumn{1}{c}{ Type of institution } \\
\hline $31.1 \%$ & 23 & Scientific community \\
$17.6 \%$ & 13 & International organisation/company \\
$14.9 \%$ & 11 & National government \\
$6.8 \%$ & 5 & International group of people \\
$6.8 \%$ & 5 & National group of people \\
$6.8 \%$ & 5 & National organisation/company \\
$6.8 \%$ & 5 & Regional group of people \\
$2.7 \%$ & 2 & International government \\
$1.4 \%$ & 1 & Regional organisation/company \\
$5.4 \%$ & 4 & Information not available \\
$100.0 \%$ & 74 & Total \\
\hline
\end{tabular}

\subsection{What are the application domains of the AP}

The calculation of the frequency of the AP per domain of application (see Table 3) demonstrated that the domain 'Learning Objects' is the most intensive producer of AP; 31 of the 74 analysed AP $(41.9 \%)$ belong to this domain. The second largest producer of AP is the 'Libraries/ Repositories' domain with ten AP (13.5\%) produced, followed by the 'cultural heritage' domain with seven AP (9.5\%) produced. The 'E-Government' and 'Cross-domain' are the fourth largest producers of AP with six AP (8.1\%) produced each; then follows the domain 'Agriculture' with five AP $(6.8 \%)$ produced. The domain that produces the least AP is the 'Science' domain with four AP (5.4\%). The 'other' domain category has produced five AP (6.6\%).
Many of the 'Learning Objects' domain AP are a subset of the IEEE LOM metadata scheme. These AP do not perform effectively at 'mixing and matching' (Heery and Patel, 2000), but they do rather a refinement of a single data schema (the IEEE LOM schema, in this case), materialising instead the oldest concept of an AP defined by Lynch (1997).

\subsection{What are the metadata schemes used by the AP}

The analyses revealed that there are 52 distinct metadata schemes used: ADL, Agent MT, agls, agmes, Availability MT, Bibio, CDWA Lite, CLD, Darwin Core, dc, dc-lib, dc collections, DCTERMS, didl, dii, edna, eGMS, eprint, foaf, FRBR, GEM, GILS, GO-ITS, GovML, GOVTALK, IEEE LOM, IMS, JHS143, LIDO, LRE AP, MARC, MARCREL, METS, METS Rights, Michael, Mix, MODs, NISO, NZGLS, ORE, OWMS, pbcore, PRISM, rmes, remsq, RSLP, SCORM, SM, tbm, TextMD and Vcard.

Detailed information about the metadata schemes can be found in Matrix-II (http://hdl.handle.net/1822/23412).

There are AP that were used as metadata schemes by other AP, so they are listed here as metadata schemes although according to Press (2004) they are not.

To understand which of these metadata schemes were used the most, we calculated the number of times each metadata scheme was used in every AP studied. To do that, for every AP we identified the metadata scheme used and added one to the counting of that particular metadata scheme, e.g. the VMAP uses the elements 'dc.title', 'dc.identifier', 'dc.creator', 'dc.description' and 'dc.subject'; we added one to the 'DC' metadata scheme; it also uses 'foaf.firstName'; we added one to the foaf metadata scheme, and so on. See Table 3 for the results of these calculations.

DC is the most used metadata scheme with $24.1 \%$, followed by IEEE LOM with $17.1 \%$. Next is DCTERMS with $15.3 \%$. agls is the fourth most used metadata scheme with $3.5 \%$, foaf follows with $2.9 \%$, and then MODs with $2.4 \%$; however, the frequency of use of the last three mentioned metadata schemes is far below the frequency of use of DC, IEEE LOM and DCTERMS. The next most used with $1.8 \%$ each are agmes, IMS, MARC and Vcard. The next most used with $1.2 \%$ each are Darwin Core, DC Collections, eprint, FRBR, LRE AP, MARCREL, MIX and RSLP. All the remaining ones have a frequency of use of $0.6 \%$.

Table 3 Frequency of AP per domain

\begin{tabular}{ccl}
\hline$\%$ & $\#$ & \multicolumn{1}{c}{ Application domain } \\
\hline $41.9 \%$ & 31 & Learning objects \\
$13.5 \%$ & 10 & Libraries/repositories \\
$9.5 \%$ & 7 & Cultural heritage \\
$8.1 \%$ & 6 & Cross-domain \\
$8.1 \%$ & 6 & E-government \\
$6.8 \%$ & 5 & Agriculture \\
$5.4 \%$ & 4 & Science \\
$6.8 \%$ & 5 & Other \\
$100.0 \%$ & 74 & Total \\
\hline
\end{tabular}


Table 4 Frequency of the metadata schemes found on the AP analysis

\begin{tabular}{|c|c|c|}
\hline \# & $\%$ & Metadata scheme \\
\hline 41 & $24.1 \%$ & $\mathrm{DC}$ \\
\hline 29 & $17.1 \%$ & IEEE LOM \\
\hline 26 & $15.3 \%$ & DCTERMS \\
\hline 6 & $3.5 \%$ & agls \\
\hline 5 & $2.9 \%$ & foaf \\
\hline 4 & $2.4 \%$ & MODs \\
\hline 3 & $1.8 \%$ & AGMES \\
\hline 3 & $1.8 \%$ & IMS \\
\hline 3 & $1.8 \%$ & MARC \\
\hline 3 & $1.8 \%$ & Vcard \\
\hline 2 & $1.2 \%$ & Darwin core \\
\hline 2 & $1.2 \%$ & DC collections \\
\hline 2 & $1.2 \%$ & eprint \\
\hline 2 & $1.2 \%$ & FRBR \\
\hline 2 & $1.2 \%$ & LRE AP \\
\hline 2 & $1.2 \%$ & MARCREL \\
\hline 2 & $1.2 \%$ & MIX \\
\hline 2 & $1.2 \%$ & RSLP \\
\hline 1 & $0.6 \%$ & $\mathrm{ADL}$ \\
\hline 1 & $0.6 \%$ & Agent MT \\
\hline 1 & $0.6 \%$ & Availability MT \\
\hline 1 & $0.6 \%$ & Bibio \\
\hline 1 & $0.6 \%$ & CDWA Lite \\
\hline 1 & $0.6 \%$ & CLD \\
\hline 1 & $0.6 \%$ & DC-Lib \\
\hline 1 & $0.6 \%$ & didl \\
\hline 1 & $0.6 \%$ & Dii \\
\hline 1 & $0.6 \%$ & Edna \\
\hline 1 & $0.6 \%$ & eGMS \\
\hline 1 & $0.6 \%$ & GILS \\
\hline 1 & $0.6 \%$ & GO-ITS \\
\hline 1 & $0.6 \%$ & GovML \\
\hline 1 & $0.6 \%$ & GOVTALK \\
\hline 1 & $0.6 \%$ & JHS143 \\
\hline 1 & $0.6 \%$ & METS \\
\hline 1 & $0.6 \%$ & METS Rights \\
\hline 1 & $0.6 \%$ & Michael \\
\hline 1 & $0.6 \%$ & NISO \\
\hline 1 & $0.6 \%$ & NZGLS \\
\hline 1 & $0.6 \%$ & ore \\
\hline 1 & $0.6 \%$ & OWMS \\
\hline 1 & $0.6 \%$ & pbcore \\
\hline 1 & $0.6 \%$ & PRISM \\
\hline 1 & $0.6 \%$ & rmes \\
\hline 1 & $0.6 \%$ & Rmesq \\
\hline 1 & $0.6 \%$ & SCORM \\
\hline 1 & $0.6 \%$ & SM \\
\hline 1 & $0.6 \%$ & tbm \\
\hline 1 & $0.6 \%$ & TextMD \\
\hline
\end{tabular}

Grouping DC and DCTERMS in one group called 'Dublin Core', this Dublin Core group is used by $39.4 \%$ of the total of the AP, thus being the most representative group. The metadata scheme IEEE LOM is the second most used (17.1\%). This value of $17.1 \%$ may be influenced by the fact that the 'Learning Objects' domain is a big 'producer' of AP (see Table 3).

From the results listed in Matrix-II (see handle http://hdl.handle.net/1822/23412):

- IEEE LOM is a metadata scheme referred in 27 of the $31(87.1 \%)$ AP of the domain 'Learning Objects', and in 19 of these $31(61.3 \%) \mathrm{AP}$ it is the only metadata scheme used. It is a very important standard for the 'Learning Objects' domain.

- IEEE LOM is only used by AP that are within the domain of 'Learning Objects', and not in any other domain.

- The metadata scheme group Dublin Core is totally cross-domain since it is used in all domains, even in the 'Learning Objects' domain where there is a strong dominance of the IEEE LOM metadata scheme.

- Since IEEE LOM metadata scheme has many common properties with the Dublin Core metadata schemes, and the latter is the pioneer in the field, we can conclude that the Dublin Core metadata schemes' properties are in fact the most used in the metadata community.

\subsection{What application domains have been producing metadata schemes}

The calculation of the frequency of use per application domain of the metadata schemes found in the 74 selected AP (see Table 5) demonstrated that the 'Libraries/ Repositories' application domain is the one that most contributes for the production of metadata schemes, having $21.6 \%$ of the total found metadata schemes. The 'Collections' application domain is the next biggest producer with $13.7 \%$ and 'Cross-Domain' and 'E-Government' application domains are the third biggest with $11.8 \%$ each. After these top four application domains metadata schemes producers we have the 'Learning Objects' application domain with $7.8 \%$, the 'Audio/Video/Multimedia' and the 'Description or/and relation of people, communities or Organisations' application domains with 5.9\% each, followed by the 'Cultural Heritage', the 'Images' and 'Scholary Communication/Publishers' application domains with 3.9\% each. The least productive metadata schemes application domains are the 'Agriculture', the 'Electronic Commerce' and the 'Science' application domains with $2.0 \%$ each.

\subsection{What are the encoding schemes used by the AP}

Our sixth goal referred in Section 1 is to verify which are the encoding schemes used by the analysed AP.

The analyses revealed that there are 13 distinct syntax encoding schemes used: AGLS Availability, AGLS Agent, DCMI Point, DCMI Box, DCMi Period, ISO 3166-1, ISO 3166-2, ISO 639-2, RFC 1766, RFC 3066, RFC 4646, URI and W3C-DTF. 
Table 5 Percentage of metadata schemes produced per application domain

\begin{tabular}{ccl}
\hline$\%$ & $\#$ & \multicolumn{1}{c}{ Application domain } \\
\hline $21.6 \%$ & 11 & Libraries/repositories \\
$13.7 \%$ & 7 & Collections \\
$11.8 \%$ & 6 & Cross-domain \\
$11.8 \%$ & 6 & E-government \\
$7.8 \%$ & 4 & Learning objects \\
$5.9 \%$ & 3 & Audio/video/multimedia \\
$5.9 \%$ & 3 & Description or/and relation of people, \\
& & communities or organisations \\
$3.9 \%$ & 2 & Cultural heritage \\
$3.9 \%$ & 2 & Images \\
$3.9 \%$ & 2 & Scholary communication, publishers \\
$2.0 \%$ & 1 & Agriculture \\
$2.0 \%$ & 1 & Electronic commerce \\
$2.0 \%$ & 1 & Science \\
$5.9 \%$ & 3 & Other \\
\hline
\end{tabular}

The analysis revealed that there are 90 distinct vocabulary encoding schemes used: DCMI Type Vocabulary, DDC, IMT, Info-eu-repo, LCC, LCSH, LCNAF, MeSH, NLM, TGN, UDC, AGLS Service, AGLS Document, AGLS Jurisdiction, AGLS Audience, PRONOM, VMAP Music Entity Type, VMAP MusicalFormType, VMAP Music GenreType, VMAP TargetedStudent, VMAP Music StyleType, VMAP Tonality, VMAP rhythmType, VMAP scoreType, VMAP documentType, VMAP learning Modality, VMAP classType, VMAP educationLevelType, VMAP conferenceType, VMAP conferenceTopic, VMAP music PerformanceType, VMAP productionType, VMAP sourceFormatType, VMAP colorType, VMAP direction Type, VMAP conservationState Type, VMAP scoreFormat Type, VMAP keyType, VMAP keyModeType, VMAP record StatusType, Eprint Entity Type Vocabulary, Eprint Access Rights, Eprint Status, Eprint Type, Darwin Core Type Vocabulary, AGROVOC, Thesaurus for the Social Sciences, Eurovoc, The National Agricultural Library's Agricultural Thesaurus, STW Thesaurus for Economics, DBPEDIA, CC REL, ISA core location vocabulary, ISA core person vocabulary, ISA core business vocabulary, Dublin Core Collection Description Accrual Method Vocabulary, Dublin Core Collection Description Frequency Vocabulary, Dublin Core Collection Description Accrual Policy Vocabulary, Aquatic Science and Fisheries Abstracts Thesaurus, BT, CABT, LEMB Thesaurus, NALT, MEDITAGRI, UNBIS Thesaurus, AGRIS Subject Categories, ASFAC Classification Scheme, CABI Codes, Global Forest Decimal Classification (GFDC), FAO Technical Knowledge Classification Scheme, Journal of Economic Literature - Classification system, Accession Number, Call Number, CODEN, DOI, International Patent Classification, International Standard Book Number - ISBN, International Standards Serial Number - ISSN, Linking
International Standards Serial Number - ISSN-L, Job Number, Microfiche Number, Patent Number, Report Number, UK Educational Levels - UKEL, FRAD User Tasks, FRBRer User Tasks, FRSAD User Tasks, DC2AP Type Vocabulary, DC2AP Format Vocabulary, Open Metadata Registry Status Vocabulary.

Detailed information about the encoding schemes can be found in Matrix-III (http://hdl.handle.net/1822/23412).

\subsection{The Singapore Framework assessment}

Our seventh goal referred to in Section 1 is to assess the Singapore Framework, i.e. to answer the question: have the AP been developed respecting the rules defined by the Singapore Framework? An application profile has followed the Singapore Framework if it has defined its functional requirements, its domain model and a description set profile.

We verified that four years after the definition of this framework, from the 74 AP selected, only five (6.7\%) fully follow this recommendation; they are (i) Dryad; (ii) IAP: Images Application Profile (developed from SWAP); (iii) SWAP: The Scholary Works Application Profile; (iv) TBMAP: Time-based media application profile and (v) VMAP: Variazioni Musical Dublin Core Application Profile. This indicates that the international metadata community has not yet actually joined the Singapore Framework for DCAP. Nevertheless, it is relevant that there is a set of AP that already developed some issues of the Singapore Framework (and are therefore on their way to achieve the recommendation). The AP ANZ LOM has defined, as an example, the functional requirements and the domain model, but not the DSP; CanCORE AP has developed the functional requirements but not the domain model nor the DSP.

\subsection{Other results}

From the analysis process we noticed that the metadata community does not use the same terminology to define the concept of 'application profile'. We have found several expressions used when referring to an $\mathrm{AP}$ :

- metadata vocabulary,

- metadata core,

- metadata standard (cf. e-GMS - e-Government Metadata Standard),

- $\quad$ schema vocabulary (cf. IOAP - Online Journal),

- semantic elements (cf. ESE - Europeana Semantic Elements),

- metadata schema (cf. ADMS - Asset Description Metadata Schema),

- web metadata standard (cf. OWMS - Overheid.nl Web Metadata Standaard).

There seems, therefore, to be little effort by the AP developers to join the DCMI terminology, which is one of the most relevant initiatives in the metadata community. 


\section{Conclusions and future work}

In this article we have presented a panoramic view of the metadata Applications Profiles (AP) developed in the last decade. We have studied 74 AP from several applications domains. We concluded that the type of institution that is the most intensive producer of AP is the 'Scientific Community' and that the 'Learning Objects' application domain is the most intensive producer among the seven different application domains identified. We also concluded that 'Dublin Core Metadata Element Set' and 'Dublin Core Terms' are, together, the most used metadata schemes (also called vocabularies), and are used in all domains of application. We also concluded that the 'IEEE LOM' metadata scheme is a dominant scheme in the 'Learning Objects' application domain, but it is not chosen by any other AP outside the borders of the 'Learning Objects' application domain. Finally, we verified that only $6.7 \%$ of the AP studied have followed the rules of the Singapore Framework.

This study also showed that the metadata community uses many different nomenclature when referring to an application profile. This dispersion around the word 'application profile' is important to notice since there seems to be little effort by the AP developers to join the DCMI (see http://dublincore.org) terminology. The work developed by DCMI groups might probably need to be disseminated through more appropriated channels.

This study was developed under the scope of a $\mathrm{PhD}$ that aims to contribute to the definition of a method for the development of DCAP. For the time being, the only guidelines available to develop a DCAP are stated in the Singapore Framework for DCAP and the DCMI Guidelines [cf. Baker et al. (2008) and Baker and Coyle (2009), respectively] and they are too brief. In fact, a study that we have recently performed shows that there is no method to develop a DCAP (cf. Curado Malta and Baptista, 2013c). A draft version of a method for the development of DCAP (Me4DCAP) was published [cf. Curado Malta and Baptista (2013a) for version 0.1 and Curado Malta and Baptista (2013b) for version 0.2]. The method is being validated through the execution of two focus groups; a final version of Me4DCAP will incorporate the outputs of the focus groups.

As future work, we intend to develop a study regarding the development of the concept of an AP over the years. We will analyse this evolution and define a timeline, locating every AP found in our study in this timeline. We also intend to study further the use of every metadata element of the most used metadata schemes referred in this study: DCMES, DCTERMS and IEEE-LOM.

The study described in this paper will be used in the development of a DCAP for the Social and Solidarity Economy (DCAP-SSE) community. The PhD work is based in a design science research methodology, through Hevner's (2007) approach; the development of the DCAP-SSE is the design cycle experimental situation of this approach.

\section{Acknowledgements}

This work is sponsored by FEDER funds through the Competitivity Factors Operational Programme (COMPETE) and by National funds through Foundation for Science and Technology (FCT) within the scope of the project: FCOMP01-0124-FFEDER-022674.

\section{References}

ADULLACT2004 (2004) Profil d'application du lom pour l'opencartable. Available online at: http://adullact.net/ docman/?group id $=63$ view=listfile dirid=68, 2004 (accessed on 15 January 2013).

Agostinho, S., Bennett, S., Lockyer, L. and Harper, B. (2004) 'Developing a learning object metadata application profile based on LOM suitable for the Australian higher education context', Australasian Journal of Educational Technology, Vol. 20, No. 2, pp.191-208.

Al-Khalifa, H.S. and Davis H.C. (2005) 'ARACORE: an Arabic learning object metadata for indexing learning resources', The First Online Metadata and Semantics Research Conference (MTSR'05), 21-30 November, pp.38-43.

Allinson, J. and Powell, A. (2006) SWAP application profile. Available online at: http://www.ukoln.ac.uk/repositories/ digirep/index/Eprints_Application_Profile (accessed on 23 October 2012).

Australian Flexible Framework (2007) Vet Metadata Application Profile (Vetadata), Australian Flexible Framework Technical Report.

Baker, T. and Coyle, K. (2009) Guidelines for Dublin Core Application Profiles. Available online at: http://dublincore. org/documents/profile-guidelines/ (accessed on 26 June 2011; confirmed on 19 August 2013).

Baker, T., Dekkers, M., Heery, R., Patel, M. and Salokhe, G. (2001) 'What terms does your metadata use? Application profiles as machine-understandable narratives', Journal of Digital Information, Vol. 2, No. 2, p.10.

Baker, T., Nilsson, M. and Johnston, P. (2008) The Singapore Framework for Dublin Core Application Profiles. Available online at: http://dublincore.org/documents/singapore-framework/ (accessed on 26 June 2011; confirmed on 19 August 2013).

Baptista, A. and Machado, A. (2001) 'Metadata usage in an online journal: an application profile', Electronic Publishing'01: 2001 in the Digital Publishing Odyssey: Proceedings of the 5th ICCC/IFIP Conference, 5-7 July, University of Kent, Canterbury, Kent, UK, pp.59--62.

Barker, E. and Ryan, B. (2003) Case Studies in Implementing Educational Metadata Standards: The Higher Level Skills for Industry Repository, CETIS: the Centre for Educational Technology Interoperability Standards Technical Report.

Barker, E. and Thomas, A. (2003) Case Studies in Implementing Educational Metadata Standards: Ferl - An Information Service Supporting the Use of It for Teaching and Learning, CETIS: The Centre for Educational Technology Interoperability Standards Technical Report.

Bountouri, L., Papatheodorou, C., Soulikias, V. and Stratis, M. (2009) 'Metadata interoperability in public sector information', Journal of Information Science, Vol. 35, No. 2, pp.204-231. 
Boyd, A., Francis, K., Haddaway, E., Perkins, J., Schlosser, M. and Spernoga, M. (2010) Ohiolink Digital Resources Commons (DRC) Metadata application profile, OhioLINK Digital Resources Management Committee (DRMC) Metadata Subcommittee Technical Report.

Buonazia, I., Masci, M. and Merlitti, D. (2007) 'The project of the Italian culture portal and its development: a case study: designing a Dublin Core Application Profile for interoperability and open distribution of cultural contents', Proceedings of the 11th International Conference on Electronic Publishing, 13-15 June ,Vienna, Austria, pp.393-404.

C2S (2009) SCORM. Available online at: http://www.conform2 scorm.com/ (accessed on 15 January 2013).

Calverley, G. and Johnston, P. (2009) Time-based Media Application Profile, Definition Phase Report, Final Version: V3.0, JISC, Bristol.

Cecilia, M.O., Muñoz, A., Sanz, M. and Van Assche, F. (2007) Audit Report on Melt Content - Version 2 3rd Part: Melt Application Profile, Ministerio de Educación y Ciencia Technical Report.

CETIS (2004) The centre for educational technology interoperability standards. Available online at: http:// zope. cetis.ac.uk/ profiles/uklomcore (accessed on 15 January 2013).

Clair, K. (2008) 'Developing an audiovisual metadata application profile: a case study', Library Collections, Acquisitions, and Technical Services, Vol. 32, No. 1, pp.53-57.

Clayphan, R. and Guenther, R. (2004) Dc-library application profile. Available online at: http://dublincore.org/documents/ library-application-profile/ (accessed on 15 January 2013).

Curado Malta, M. and Baptista, A.A. (2013a) 'Me4DCAP V0.1: a method for the development of Dublin Core Application Profiles', Journal of Information Science and Use, Vol. 33, No. 2, pp.161-171.

Curado Malta, M. and Baptista, A.A. (2013b) 'A method for the development of Dublin Core Application Profiles (Me4DCAP V0.2): detailed description', Proceedings of the International Conference on Dublin Core and Metadata Applications, 2-6 September, Lisbon, pp.90-103.

Curado Malta, M. and Baptista, A.A. (2013c) 'State of the art on methodologies for the development of a metadata application profile', International Journal of Metadata, Semantics and Ontologies, Vol. 8, No. 4, pp.332-341.

da Matta Vegi, L.F. (2012) Technical Description - dcap2ap, Technical Report, Universidade Federal de Viçosa - Centro de Ciências Exatas e Tecnolóogicas - Departamento de Informática.

DCMI (2011) Dcmi glossary. Available online at: http://wiki. dublincore.org/index.php/Glossary (accessed on 11 July 2013, confirmed on 19 August 2013).

DCMI (2012) Dublin core education application profile (working draft of v0.4). Available online at: https://docs. google. com/Doc?id=dn8z3gs_38cgwkvv (accessed on 2 June 2012).

de La Passadière, B. and Jarraud, P. (2004) 'Manuel, a lom application profile for $\mathrm{c} @$ mpusciences ${ }^{\circledR}$ ', Sciences et Technologies de l Information et de la Communication pour l Éducation et la Formation, 11.

Digital Repository Infrastructure Vision for European Research (2011) Driver. Available online at: http://www.driverrepository.eu/ (accessed on 15 January 2013).

Dublin Core Collections Task Group (2007) Dublin core collections application profile. Available online at: http:// dublincore.org/groups/collections/collection-applicationprofile/ (accessed on 15 January 2013).
Dublin Core Government Task Group (2013) Dc-gov application profile. Available online at: http://dublincore.org/groups/ government/profile-200111.shtml (accessed on 15 January 2013).

Eadie, M. (2008) 'Towards an application profile for images', Ariadne, No. 55

edna.edu.au (2006) Edna resources - metadata application profile. Available online at: http://apps-new.edna.edu.au/edna retired edna/go/resources/metadata/edna_metadata_profile.html.

Education Services Australia (2011) Metadata application profile: ANZ-LOM. Available online at: http://www.ndrl.edu.au/ (accessed 15 January 2013).

FAO (n.d.a) Guidelines for Exchanging Event Metadata: The agevent Application Profile, FAO Technical Report.

FAO (n.d.b) Guidelines for Exchanging Job Vacancy Metadata: The Ag-Job Application Profile, FAO Technical Report.

Feliciati, P. (2010) 'Towards a sound management of digital culture. Metadata schemes and application profiles for digital repositories', 2nd International Symposium on 'Digitization of Cultural Heritage of Bosnia and Herzegovina', 17-18 May, Sarajevo, Bosnia Herzegovina.

Fisheries and Aquaculture Department (2011) Fisheries metadata element set (FiMES). Available online at: http://www. fao.org/fishery/topic/166231/en (acessed on 4 June 2012).

George, Y., Akli, L., Chang, A., Collins, C., Gull, K., Gough, N., Lowy, M., Matyas, M., Muramatsu, B., Musante, S. and Taylor, J. (2011) Ben (Bioscieducation Network) Metadata Specification - Version 1.3.1, AAAS for the Bioscieducation Network Collaborative 2002 Technical Report.

Godby, C. (2004) 'What do application profiles reveal about the learning object metadata standard', Ariadne, No. 41.

Government of Ontario (2005) Web Metadata StandardGovernment of Ontario IT Standards (GO-ITS), Document No. 43, Ministry of Government Services Technical Report.

Greenberg, J., White, H., Carrier, S. and Scherle, R. (2009) 'A metadata best practice for a scientific data repository', Journal of Library Metadata, Vol. 9, Nos. 3-4, pp.194-212.

Group, D.C.C.D.T. (2007) Asset description metadata schema. Available online at: http://joinup.ec.europa.eu/asset/ adms/ release/100 (accessed on 15 January 2013).

Haslhofer, B. and Isaac, A. (2011) 'data.europeana.eu: the Europeana linked open data pilot', International Conference on Dublin Core and Metadata Applications, 21-23 September, The Hague, The Netherlands, pp.94-104.

Heery, R. and Patel, M. (2000) 'Application profiles: mixing and matching metadata schemas', Ariadne, Vol. 2, pp.27-31.

Hevner, A. (2007) 'The three cycle view of design science research', Scandinavian Journal of Information Systems, Vol. 19, No. 2, pp.87-92.

Iglesias, C.A., Garijo, M., Molina, D. and de Juan, P. (2009) 'VMAP: A Dublin Core Application Profile for musical resources', in Satori, F., Sicilia, M.A. and Manouselis, N. (Eds): Metadata and Semantic Research: Third International Conference, MTSR 2009, CCIS Vol. 46, Springer-Verlag, Berlin, pp.1-12.

IT-Research, N.N. (2012) Norsk lom-profil - normlom. Available online at: http://www.itu.no/filestore/NSSL/NORLOM/ NORLOM_v1_0.pdf (accessed 15 January 2013).

Johnston, P. (2006) Michael-EU Dublin Core Application Profile. Available online at: http://www.ukoln.ac.uk/metadata/ michael/ michael-eu/dcap/ (accessed on 15 January 2013). 
Kemman, M. (2009) Mpeg21 DIDL Application Profile for institutional repositories. Available online at: http://wiki. surf.nl/display/standards/MPEG21+DIDL+Application+Profile + for+Institutional+Repositories (accessed on 13 January 2013).

Khazraee, E. and Park, J. (2010) 'Lessons learned from EIAH metadata application profile (EMAP)', Cataloging \& Classification Quarterly, Vol. 48, No. 5, pp.472-485.

LOREnet (2010) Lore lom. Available online at: http://wiki.surf. $\mathrm{nl} /$ display/standards/LORElom (accessed on 15 January 2013).

Lourdi, I. and Papatheodorou, C. (2004) 'A metadata application profile for collection-level description of digital folklore resources', Proceedings of the 15th International Workshop on Database and Expert Systems Applications, pp.90-94.

LTSO, C.W-L. (2012) Cancore metadata: overview. Available online at: http://www.cen-ltso.net/main.aspx?put=214\& AspxAutoDetectCookieSupport=1.

Lynch, C.A. (1997) 'The z39.50 information retrieval standard part i: a strategic view of its past, present and future', D-Lib Magazine.

Manouselis, N. and Costopoulou, C. (2006) 'A metadata model for e-markets', International Journal of Metadata, Semantics and Ontologies, Vol. 1, No. 2, pp.141-153.

Manouselis, N., Kastrantas, K. and Tzikopoulos, A. (2007) 'An IEEE LOM application profile to describe training resources for agricultural \& rural SMES', Proceedings of the 2nd International Conference on Metadata and Semantics Research (MTSR'07), 1-2 October, Corfu, Greece.

Manouselis, N., Salokhe, G. and Keizer, J. (2009) 'Comparing different metadata application profiles for agricultural learning repositories', Post-proceedings of the 2nd International Conference on Metadata and Semantics Research, MTSR 2007, 1-2 October, Corfu Island, Greece, pp.469-479.

Manouselis, N., Najjar, J., Kastrantas, K., Salokhe, G., Stracke, C. and Duval, E. (2010) 'Metadata interoperability in agricultural learning repositories: an analysis', Computers and Electronics in Agriculture, Vol. 70, No. 2, pp.302-320.

Marzal García-Quismondo, M., Calzada Prado, J. and Cuevas Cerveró, A. (2006) 'Desarrollo de un esquema de metadatos para la descripción de recursos educativos: el perfil de aplicación mimeta', Revista española de documentación cientificaca, Vol. 29, No. 4, pp.551-571.

Massart, D. and Shulman, E. (2011) Learning Resource Exchange Metadata Application Profile Version 4.7, European Schoolnet Technical Report.

Moen, W., Huang, J. and McCotter, M. (2010) 'Extraction and parsing of herbarium specimen data: exploring the use of the Dublin Core Application Profile framework', Proceedings of IConference 2010, 3-6 February, University of Illinois at Urbana-Champaign, IL, pp.154-160.

Nevile, L. and Lissonnet, S. (2005) 'Was CIMI too early? Dublin Core and Museum Information: metadata as cultural heritage data', International Conference on Dublin Core and Metadata Applications, 12-15 September, Madrid, Spain, pp.31-38.

New Zealand State Services Commission (2002) NZGLS Metadata Element Set - Version 2.1, New Zealand State Services Commission Technical Report.

Nikos, M. and Axel, M. (2010) Application Profiles for Describing Cerorganic, Mediterranean Agronomic Institute of Chania Technical Report.

Nilsson, M. (2008) Description set profiles: a constraint language for Dublin Core Application Profiles (DCMI Working Draft). Available online at: http://dublincore.org/documents/ 2008/ 03/31/dc-dsp/.
Nilsson, M., Baker, T. and Johnston, P. (2009) Interoperability levels for Dublin Core Metadata. Available online at: http://dublincore.org/documents/interoperability-levels/ (accessed on 26 June 2011; confirmed on 19 August 2013).

Normetic (2013) Normetic. Available online at: http:// www. normetic.org/Nouvel-article.html (accessed on 15 January 2013).

National Archives of Australia (2010) AGLS Metadata StandardPart II: Usage Guide, National Archives of Australia Technical Report.

Onyancha, I., Keizer, J. and Katz, S. (2001) 'A Dublin Core Application Profile in the agricultural domain', International Conference on Dublin Core and Metadata Applications, 22-26 October, Tokyo, Japan, pp.185-192.

Open Archives Initiative (2008) Open Archives Initiative - object reuse and exchange. Available online at: http://www. openarchives.org/ore/ (accessed on 14 January 2013).

Palavitsinis, N., Kastrantas, K. and Manouselis, N. (2009) 'Interoperable metadata for a federation of learning repositories on organic agriculture and agroecology', Proceedings of Joint International Agricultural Conference (JIAC2009), 6-8 July, Wageningen, The Netherlands.

Patra, C. (2009) Application profile for ceramic resources. Available online at: http://metadataregistry.org/schema/ show/id/19.html (accessed on 15 January 2013).

Powell, A. (2009) RDN/LTSN LOM application profile. Available online at: http://www.intute.ac.uk/publications/rdn-ltsn/ap/ (accessed on 3 June 2012).

Powell, A., Nilsson, M., Naeve, A., Baker, T. and Johnston, P. (2007) DCMI abstract model. Available online at: http://dublincore.org/documents/2007/06/04/abstract-model/ (accessed on 26 June 2011).

Press, N. (2004) Understanding Metadata, NISO Press Booklets, Baltimore, MD, USA.

Rodriguez Artacho, M., Colin, J-N., Ilomäki, L., Jaakkola, T., Lakkala, M., Lehtinen, E., Nurmi, S., Paavola, S., Panzavolta, S., Robinson, M., Roozen, F., Sanz, M., Simon, J. and Trigari, M. (2003) The CELEBRATE metadata application profile, CELEBRATE Technical Report.

Ruddy, D. (2010) 'Developing a metadata exchange format for mathematical literature', in Sojka, P. (Ed.): Towards a Digital Mathematics Library, Paris, France, pp.27-36.

Rushing, A., Koenig, J., Mitchell, A., Moen, W., Strawn, T. and Thomale, J. (2008) Texas digital library descriptive metadata guidelines for electronic theses and dissertations, version 1.0, prepared for and published by the Texas Digital Library, Denton, TX, USA.

Salokhe, G., Pesce, V. and Liesthout, J. (2008) Organization Metadata Application Profile, FAO Technical Report.

ScoLOMFR (2011) Schema de description des ressources num eriques de l'enseignement scolaire. Available online at: http://www.lom-fr.fr/scolomfr (accessed on 15 January 2013).

Slater, J. (2001) Guidelines for Failte Metadata, Technical Report, Facilitating Access to Information on Learning Technology for Engineers.

Stuempel, H., Salokhe, G., Aubert, A., Keizer, J., Nadeau, A., Katz, S. and Rudgard, S. (2009) 'Metadata application profile for agricultural learning resources', in Sicilia, M-A. and Lytras, M.D. (Eds): Metadata and Semantics, Springer, USA, pp.499-507.

SUB Renardus Team (2002) Renardus - the academic subject gateway service in Europe. Available online at: http:// renardus.sub.unigoettingen.de/renap/ (accessed on 15 January 2013).

UK-online (2008) e-Government Metadata Standard, Technical Report, Cabinet Office - Office of the e-Envoy. 
U.S. National Library of Medecine (2004) National Library of Medecine metadata set. Available online at: http://www. nlm.nih. gov/tsd/ cataloging/metafilenew.html (accessed on 14 January 2013).

voor Burgers, I.E-O. (2011) Normatieve specificatie owms 4.0 overheid.nl web metadata standaard, Ministerie van Binnenlandse Zaken en Koninkrijksrelaties Technical Report.

W3C (2010) RDF - W3C standards. Available online at: http:// www.w3.org/RDF/ (acessed on 14 January 2012; confirmed on 9 February 2013).

W3C (2012) Semantic web. Available online at: http://www.w3. org/standards/semanticweb/ (accessed on 14 January 2012; confirmed on 19 August 2013).
Ward, N. (2003) 'Creating a metadata application profile: a case study of the learning federation experience', Proceedings of the EDUCAUSE in Australasia 2003 Conference, 6-9 May, Adelaide, Australia, pp.662-668.

Wilson, K., Billington, L., Moir, S. and Carpenter, S. (2007) 'Development of a metadata application profile at the State Library of New South Wales', Proceedings of the 13th Information Online Conference, Australian Library and Information Association, Sydney, Library Papers, p.4.

Zschocke, T., Beniest, J., Paisley, C. and Najjar, J. (2009) 'The LOM application profile for agricultural learning resources of the CGIAR', International Journal of Metadata, Semantics and Ontologies, Vol. 4, No. 1, pp.13-23. 
Appendix A List of analysed application profiles per domain of application

\begin{tabular}{|c|c|c|}
\hline \multicolumn{3}{|c|}{ Agriculture } \\
\hline Acronym & Singapore & Ref. \\
\hline \multicolumn{3}{|l|}{ Year: 2005} \\
\hline AGRIS & No & Onyancha et al. (2001) \\
\hline \multicolumn{3}{|l|}{ Year: 2008} \\
\hline Organisation AP & No & Salokhe et al. (2008) \\
\hline \multicolumn{3}{|l|}{ Year: 2011} \\
\hline FiMES & No & Fisheries and Aquaculture Department (2011) \\
\hline \multicolumn{3}{|l|}{ Year: $\mathbf{n} / \mathbf{a}$} \\
\hline Ag-Event AP & No & FAO (n.d.a) \\
\hline Ag-Job AP & No & FAO (n.d.b) \\
\hline \multicolumn{3}{|c|}{ Cross-domain } \\
\hline Acronym & Singapore & Ref. \\
\hline
\end{tabular}

\begin{tabular}{|c|c|c|}
\hline Year: 2002 & & \\
\hline NZGLS & No & New Zealand State Services Commission (2002) \\
\hline \multicolumn{3}{|l|}{ Year: 2006} \\
\hline DC-EM AP & No & Manouselis and Costopoulou (2006) \\
\hline \multicolumn{3}{|l|}{ Year: 2008} \\
\hline Audiovisual AP & No & Clair (2008) \\
\hline \multicolumn{3}{|l|}{ Year: 2009} \\
\hline TBM-AP & Yes & Calverley and Johnston (2009) \\
\hline VMAP & Yes & Iglesias et al. (2009) \\
\hline \multicolumn{3}{|l|}{ Year: 2010} \\
\hline AGLS MS & No & National Archives of Australia (2010) \\
\hline \multicolumn{3}{|c|}{ Cultural heritage } \\
\hline Acronym & Singapore & Ref. \\
\hline \multicolumn{3}{|l|}{ Year: 2001} \\
\hline MAG & No & Feliciati (2010)) \\
\hline \multicolumn{3}{|l|}{ Year: 2004} \\
\hline QuinkMap & No & Nevile and Lissonnet (2005) \\
\hline Folklore Description AP & No & Lourdi and Papatheodorou (2004) \\
\hline \multicolumn{3}{|l|}{ Year: 2007} \\
\hline $\mathrm{PICO}$ & No & Buonazia et al. (2007) \\
\hline \multicolumn{3}{|l|}{ Year: 2010} \\
\hline EMAP & No & Khazraee and Park (2010) \\
\hline \multicolumn{3}{|l|}{ Year: 2012} \\
\hline ESE & No & Haslhofer and Isaac (2011) \\
\hline EDM & No & Haslhofer and Isaac (2011) \\
\hline \multicolumn{3}{|c|}{ E-government } \\
\hline Acronym & Singapore & Ref. \\
\hline \multicolumn{3}{|l|}{ Year: 2005} \\
\hline GO-WMES & No & Government of Ontario (2005) \\
\hline \multicolumn{3}{|l|}{ Year: 2006} \\
\hline DC-Gov & No & Dublin Core Government Task Group (2013) \\
\hline \multicolumn{3}{|l|}{ Year: 2008} \\
\hline e-GMS & No & UK-online (2008) \\
\hline PSI AP & No & Bountouri et al. (2009) \\
\hline \multicolumn{3}{|l|}{ Year: 2010} \\
\hline OWMS & No & voor Burgers (2011) \\
\hline \multicolumn{3}{|l|}{ Year: 2012} \\
\hline ADMS & No & Group (2007) \\
\hline
\end{tabular}


Appendix A List of analysed application profiles per domain of application (continued)

\begin{tabular}{|c|c|c|}
\hline \multicolumn{3}{|c|}{ Learning Objects } \\
\hline Acronym & Singapore & Ref. \\
\hline \multicolumn{3}{|l|}{ Year: 2002} \\
\hline ANZ LOM & No & Education Services Australia (2011) \\
\hline FAILTE & No & Slater (2001) \\
\hline \multicolumn{3}{|l|}{ Year:2003 } \\
\hline Celebrate AP & No & Rodriguez Artacho et al. (2003) \\
\hline CanCore AP & No & LTSO (2012) \\
\hline FERL & No & Barker and Thomas (2003) \\
\hline HLSI & No & Barker and Ryan (2003) \\
\hline \multicolumn{3}{|l|}{ Year:2004 } \\
\hline ManUel & No & de La Passadière and Jarraud (2004) \\
\hline OpenCartable & No & ADULLACT2004 (2004) \\
\hline UK LOM Core & No & CETIS (2004) \\
\hline SCORM & No & C2S (2009) \\
\hline \multicolumn{3}{|l|}{ Year:2005 } \\
\hline Ag-LR & No & Stuempel et al. (2009) \\
\hline AraCore & No & Al-Khalifa and Davis (2005) \\
\hline NORMLOM & No & IT-Research (2012) \\
\hline TLF AP & No & Ward (2003) \\
\hline \multicolumn{3}{|l|}{ Year:2006 } \\
\hline MIMETA & No & Marzal García-Quismondo et al. (2006) \\
\hline \multicolumn{3}{|l|}{ Year:2007 } \\
\hline DC-Edu & No & DCMI (2012) \\
\hline Vedata & No & Australian Flexible Framework (2007) \\
\hline MELT & No & Cecilia et al. (2007) \\
\hline ReGov & No & Manouselis et al. (2007) \\
\hline \multicolumn{3}{|l|}{ Year:2008 } \\
\hline Normetic & No & Normetic (2013) \\
\hline \multicolumn{3}{|l|}{ Year:2009 } \\
\hline Organic Edu.net & No & Palavitsinis et al. (2009) \\
\hline CG LOM & No & Zschocke et al. (2009) \\
\hline RLLOMAP & No & Powell (2009) \\
\hline \multicolumn{3}{|l|}{ Year:2010 } \\
\hline CerOrganic AP & No & Nikos and Axel (2010) \\
\hline LORELOM & No & LOREnet (2010) \\
\hline scoLOMFR & No & ScoLOMFR (2011) \\
\hline \multicolumn{3}{|l|}{ Year:2011 } \\
\hline LREAP & No & Massart and Shulman (2011) \\
\hline BEN & No & George et al. (2011) \\
\hline
\end{tabular}


Appendix A List of analysed application profiles per domain of application (continued)

\begin{tabular}{|c|c|c|}
\hline \multicolumn{3}{|c|}{ Libraries/repositories } \\
\hline Acronym & Singapore & Ref. \\
\hline \multicolumn{3}{|l|}{ Year: 2002} \\
\hline RENAP & No & SUB Renardus Team (2002) \\
\hline \multicolumn{3}{|l|}{ Year: 2004} \\
\hline DC-LIB & No & Clayphan and Guenther (2004) \\
\hline NLM MS & No & U.S. National Library of Medecine (2004) \\
\hline \multicolumn{3}{|l|}{ Year: 2006} \\
\hline Michael-eu DCAP & No & Johnston (2006) \\
\hline \multicolumn{3}{|l|}{ Year: 2007} \\
\hline DC-CDAP & No & Dublin Core Collections Task Group (2007) \\
\hline MAP & No & Wilson et al. (2007) \\
\hline \multicolumn{3}{|l|}{ Year: 2008} \\
\hline OAI-DC & No & $\begin{array}{l}\text { Digital Repository Infrastructure Vision for European Research } \\
\text { (2011) }\end{array}$ \\
\hline TDL ETD MOS & No & Rushing et al. (2008) \\
\hline \multicolumn{3}{|l|}{ Year: 2009} \\
\hline MPEG-21 DIDL & No & Kemman (2009) \\
\hline \multicolumn{3}{|l|}{ Year: 2010} \\
\hline DRC AP & No & Boyd et al. (2010) \\
\hline \multicolumn{3}{|c|}{ Science } \\
\hline Acronym & Singapore & Ref. \\
\hline \multicolumn{3}{|l|}{ Year: 2006} \\
\hline SWAP & Yes & Allinson and Powell (2006) \\
\hline \multicolumn{3}{|l|}{ Year: 2010} \\
\hline APIARY AP & No & Moen et al. (2010) \\
\hline DRYAD & Yes & Greenberg et al. (2009) \\
\hline MLAP & No & Ruddy (2010) \\
\hline \multicolumn{3}{|c|}{ Other } \\
\hline Acronym & Singapore & Ref. \\
\hline \multicolumn{3}{|l|}{ Year: 2001} \\
\hline IOAP & No & Baptista and Machado (2001) \\
\hline \multicolumn{3}{|l|}{ Year: 2008} \\
\hline OAI-ORE & No & Open Archives Initiative (2008) \\
\hline \multicolumn{3}{|l|}{ Year: 2009} \\
\hline CRAP & No & Patra (2009) \\
\hline \multicolumn{3}{|l|}{ Year: 2010} \\
\hline IAP & Yes & Eadie (2008) \\
\hline \multicolumn{3}{|l|}{ Year: 2012} \\
\hline DC2AP & No & da Matta Vegi (2012) \\
\hline
\end{tabular}


Appendix B Classification tables

Table B1 Classification of type of institutions or communities that developed AP

Type Description

Scientific community A project developed in one or several universities

Regional group of people A set of people that work within the scope of a region inside a country (e.g. Texas, Minho, Bretagne, Andaluzia)

National group of people A set of people that work within the scope of a country

International group of people

A set of people that work beyond country borders

National government

A ministry or any other kind of governmental institution

International government

A set of governments in different countries or federal government (e.g. European Union; a group of ministries in different countries)

Regional organisation/company An organisation or company that works within the scope of a region inside a country

National organisation/company An organisation or company that works within the scope of a country

International

organisation/company

Information not available
A organisation or company that works in the world, in different countries (e.g. FAO)

If there is no information concerning the type of institution
Table B2 Classification of domain of application of the AP

Domain

Agriculture

Cultural heritage

Cross-domain

e-government

Learning Objects

Libraries/repositories

Science

Other

Table B3 Classification of the metadata schemes used by the AP

Domain

Agriculture

Audio/video/multimedia

Collections

Cross-domain

Cultural heritage

Description or/and relation of people, communities or organisations

E-commerce

E-government

Images

Learning Objects

Libraries/repositories

Scholarly communication, publishers

Science

Other 